\title{
25
}

\section{Building capacity for Information Technology in educational management in developing countries}

\author{
Adrie J. Visscher \\ University of Twente \\ Department of Educational Science and Technology \\ P. O. Box 217 \\ 7500 AE Enschede \\ The Netherlands \\ E-mail:Visscher@edte.utwente.nl
}

\begin{abstract}
Information Technology has important benefits for the administration and management of educational institutions. Important aspects of School Information System (SIS) planning and implementation are the approaches used for analyzing the school from an information processing perspective, the implementation process itself, and the degree to which the SIS matches essential school organizational characteristics. In this paper each aspect is elaborated and the importance of its relation to the use and effects of SISs for developing countries is explained.
\end{abstract}

Keywords

Developing countries, systems design, management, information handling, capacity building

Experience gained through research and development activities in Hong Kong, Australia, New Zealand, Great Britain, Israel, the USA and The Netherlands over the last ten years (Visscher, 1991; 1992; 1994; 1996) shows that Information Technology and Educational Management (ITEM) is a valuable tool for developing countries. ITEM, the use of technology for the support of clerical and management 
activities in educational institutions, may improve the efficiency and effectiveness of school staff. Efficiency is the relation between the input for and the output of data, resulting in savings for educational institutions. School effectiveness, the degree to which the school goals are realized, may also be positively influenced. A discussion of school effectiveness as well as important factors in the design and introduction of SISs will be discussed to help developing countries determine a strategy that will enable them to benefit from computerized data management.

\section{THE NATURE OF SCHOOL INFORMATION SYSTEMS AND THEIR POTENTIAL BENEFITS}

A computerized SIS is an information system based on one or more computers with a database and one or more computer applications. Together the system enables computer-assisted storage, manipulation, retrieval and distribution of school data.

The contents of the SIS and the support it can provide depends, among other things, on the number of applications (e.g. student registration, personnel registration, timetable construction, etc.) it includes. The nature of the applications can differ considerably. Sometimes they only support clerical and school office activities; in other cases they also assist school managers in their work.

Registering data leads to a database with data concerning the organizational environment. Clerical staff retrieve and manipulate data from the database. An SIS framework is presented that was constructed on the basis of an analysis of Dutch schools for secondary education. The framework consists of seven registrational (Figure 1) and four management (Figure 2) school information subsystems.

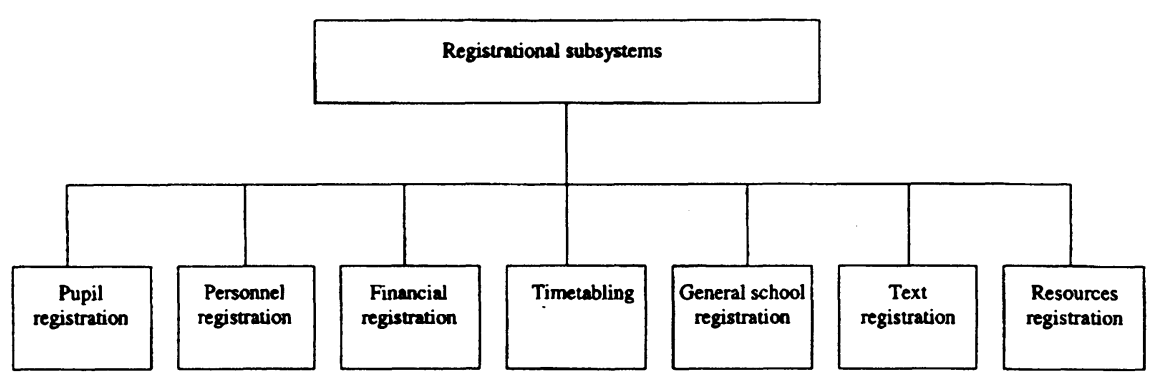

Figure 1. Registrational subsystems

The registrational subsystems support the use and manipulation of student, financial, personnel and other data. The student registration subsystem concerns the heart of the school office - student data with regard to enrolmnt, absenteeism, student counseling, testing and deletion. 


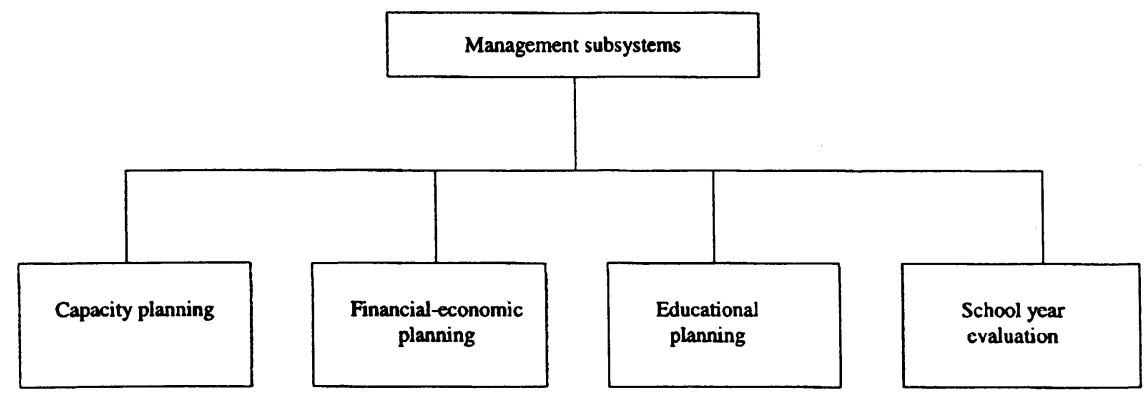

Figure 2. Management subsystems

The four management subsystems shown in Figure 2 support different types of activities:

- capacity planning: planning physical facilities, staff and technical facilities. The computer can assist the development of plans by providing reports regarding the current situation, computing the number of staff needed and providing information on the effects of alternative capacity-planning measures;

- educational planning: allocating the number of lessons to staff members and constructing the timetable;

- financial planning: estimating the expected revenues and their proposed allocation;

- school year evaluation: evaluating what has been planned. The subsystem uses financial, social and educational data to answer pertinent evaluation questions such as, 'What percent of students move to other schools?' 'What are their grades and did they pass the final examination?', or 'What budgets have been exceeded over the past five years and how many times has this occurred?'

\section{1 (Expected) effects of system use}

The use of SISs is expected to improve school efficiency and effectiveness.

Efficiency may be influenced positively as a result of:

- single entry and multiple use of school data; in the pre-computer situation data were registered several times at different locations;

- computer-assisted transfer of data on various internal and external forms;

- computer-supported data manipulation;

- computer-assisted data exchange with external bodies and institutions.

Although it is very difficult to prove time and human resources savings through educational research, the above mentioned benefits are plausible. More effectiveness may be possible in schools for a number of reasons:

- improved efficiency enables the carrying out of activities that, in former days, were impossible because school staff were occupied with registrational activities; 
- $\quad$ staff can find better solutions for structured allocation problems (e.g. timetables) because the computer can now show alternative solutions from which the best one can be chosen;

- $\quad$ SISs enable better process control; in case certain standards are exceeded (e.g. the number of times a student is allowed to play truant, a student/class achievement level, department budgets, etc.), the computer can observe that something is going wrong and requires the attention of school staff. A more timely reaction may help schools function more effectively;

- policy development and evaluation. If school data are registered in a database that enables investigating the relationship between variables (e.g. between truancy and student achievement) and more informed school policy making becomes possible. Moreover, it becomes easier to study the effects of policy measures (for instance whether the number of truants has been reduced or not).

Just as it is very difficult to prove efficiency improvements empirically, more school effectiveness as a consequence of the use of SISs is surrounded by obstacles. However, the fact that the majority of schools using an SIS would refuse to return to the old manual system confirms our positive opinion on the impact of SISs. Schools are especially enthusiastic about efficiency improvements; effectiveness improvements have not yet been demonstrated. COUNTRIES

In the design and introduction of computer-assisted management information systems many variables and relationships between the variables play a role. In the discussion about this topic Figure 3 may be helpful. 


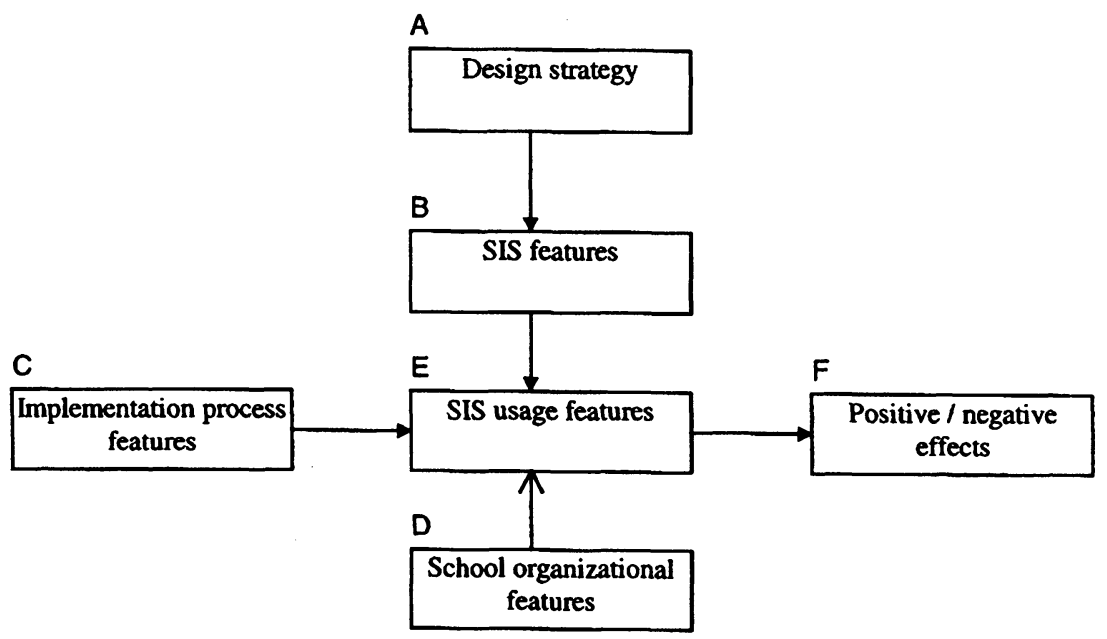

Figure 3. The variable groups influencing school information system usage and its effects

Figure 3 consists of six groups of variables: the design strategy, the SIS features, the extent of SIS use, the features of the implementation process, the school organizational features, system use, and the positive and negative effects of system use. The arrows between the variable groups show that system use is supposed to be determined by information system quality features - which result from the chosen design strategy - as well as from the nature of the implementation process (the training users receive), and of the organization into which the SIS is introduced. The (un)planned effects are considered to be a function of the intensity with which and way in which a SIS is used at various school levels.

With respect to the central question of this paper, what is a good SIS design and implementation strategy for developing countries constitutes, Figure 3 shows the interrelatedness of many factors - each of the six variable groups consists of many variables. Neither the information system quality nor the implementation process, or the school features alone can fully explain how the SIS is used and which impact system usage has. The impact of the system depends on system usage features, which are dependent on the variables in the blocks A, B , C and D. The combination of variables is decisive for what happens.

Although much more empirical research on the contents of the blocks and desirable combinations of variables is needed some know-how regarding variables 'that matter' is available. Each block in Figure 3 is discussed now.

\subsection{Design strategy}

The history of ITEM shows an evolution in the strategies for designing SISs. Important dements of the strategy concem the automation goals strived for, the way in which the organisational analysis tha forms the basis for the SIS definition is carried out and how the standardisation/flexibility problem - to develop an SIS that is standard but flexible enough to be used in as many schools as possible - is addressed. 
In the first stages pioneer teachers developed one or a few computer applications to improve the efficiency of school office activities. System analysis and design were not very professional at that time. Their strategy may be labelled a 'first things first' approach. One started with developing the first application (e.g. student registration). When it had been realised the search for another application started and so on. The software was designed for use in a small number of schools and was tailor-made for that school.

In the next stage software vendors entered the arena, developing more clerical applications with the goal to sell their standard SISs to as many schools as possible. Although designers operated more professionally than before, still no profound analysis of the school has been carried out as a basis for system development. Though complete integration of the SIS modules was still distant there was more attention to the relationships between the various applications.

The third and last group of SIS designers strived for sophisticated comprehensive systems. In addition to the efficiency of clerical work, increased school effectiveness became an automation goal. Designers became aware that SISs can support managers in their work in valuable ways, and the goal is to determine all useful forms of support for clerical and management school staff. To accomplish this goal a fundamental design strategy (Visscher, 1994) is chosen to draw a picture of the entire school in terms of the information demands at various school levels, the information flows between these levels, and between the school and external organisations.

Once the overview is available and the architecture - modules and mutual relationships - of the entire SIS is known, the modules it consists of can be developed in a stepwise manner. User participation in system design to balance the role of computer science experts is important. Realising quality systems also requires extensive formative evaluation of prototype-SISs in the intended implementation situation.

Such an evaluation of the match between user-context characteristics and SIS features must start early and not stop before the iterative test-redesign cycles have led to an SIS that is appreciated by designers and users. In other words, the cycles ideally do not stop before the high-perceived SIS quality equals the high-actual quality. Too often too little time is spent on analysis, design and the systematic collection of user feedback as a basis for SIS development. As a result resources are wasted to a certain degree, users complain, become frustrated and do not benefit fully from the SIS.

The SISs designed in the third stage are meant to be used in as many schools as possible. However, although the SIS is standard, wherever possible it has been tried to achieve a compromise between standardisation and the specific features of each school, which asks for flexibility. Schools can choose the modules they need and in the modules user options are created. The use of relational databases in combination with query languages, enables users to determine for themselves which specific information they retrieve from the SIS.

The fundamental approach of the third stage can be observed in countries that have started early with ITEM. If a developing country plans to build capacity in this area it definitely must start with the fundamental, participative, centralised develop one system for all schools at a central level - design approach. It will be expensive but the cost and effort invested will return the investment by important 
school efficiency and school effectiveness improvements, It also avoids the loss of capital that would result from developing SISs in less profound ways, which after some time will prove to be unsatisfactory and cannot be optimised.

\subsection{SIS features}

Although there is little empirical research on which SIS features influence SIS use some ideas on factors 'that matter' can be presented. Systems that from a technical point of view are very sophisticated may neither be appreciated nor used by the target group because the systems do not consider the essential features of the user context and are therefore perceived to be inadequate.

Important quality aspects of SISs are the extent and quality of the support they offer to school staff in terms of the information handling activities supported as well as how the information handling has been accomplished. Other SIS quality aspects concern the ease-of-use of the SIS for the average user (how easy it is to enter, retrieve and output data), the transparency of the SIS and the difficulty of navigating through it. System reliability (does it always work?), accuracy and speed also influence the extent of system use. The appeal and added value of the SIS information in comparison with other ways of data handling are also important considerations. If the analysis of computer data consumes a lot of time and effort but does not help much users probably will not use the SIS intensely.

\subsection{Implementation process features}

'People variables' prove to be crucial in the process of introducing SISs. The motivation of users for the innovation influences the success of the introduction of the SIS into schools and should therefore receive the required attention from those who support users in implementing the system. Related to this are opportunities for users to influence system implementation. A project champion encouraging the innovation and solving problems also seems to increase the chance of successful implementation (Fung, 1991). Limited resources to innovate frequently overload those involved in the innovation process. A careful management of the innovation process is crucial: clear innovation goals and a feasible innovation pace are essential. Schools need time to assimilate a SIS module into their organisation.

Visscher (1994) says a school-based project team, consisting of a group of school staff with the relevant SIS know-how should be convened and dispersed throughout the school. Thus, if one staff member leaves the school this will not cause big problems for the continuation of ITEM.

Support during the innovation process is also very important for quick answers to user requests for information that rise when they invest in this new, uncertain activity. Clear manuals can also help users when direct support is impossible.

Though user-training is essential, it usually does not receive the attention it requires. The training is often too technical (the use of software and hardware) and neither focuses on computer-supported management activities nor on how the system output must be interpreted and used in school decision-making. If schools are not coached on such problems matters the probability that powerful SISs with management supporting capacity are only used as automated card-trays supporting clerical school staff increases. 


\subsection{School organisational factors}

The extent to which the school leader supports the innovation is probably influenced by what $\mathrm{s} / \mathrm{he}$ knows about the potential of these systems and his/her skills and experience in this field is decisive for the success of introducing SISs into schools. An enthusiastic school leader stimulates system use, takes and supports initiatives in this area, allocating resources (hardware, software, time) to it.

The readiness of schools to benefit fully from the SIS, especially for higher-order management activities, will also influence the extent of system use. In schools that do not meet the conditions for this form of system use rather drastic organisational development work is necessary to move to that level of system use.

School managers receive information from a variety of sources and their work consists of many short activities. Profound problem analysis is rare; the use of quick, informal, verbal information, matching with their own views and triggering actions is very common. Moreover, they are not experienced in using quantitative data. Such characteristics of the school organisation do not fit with the features of SISs very well. So attention has to be paid to the perceptions of school managers who must learn to value the power of SISs and to experience how they can benefit from SISs in addition to the informal sources they use.

Organisational problems are not taken away by introducing a SIS. To enhance the successful introduction of SISs at clerical and management school level serious organisational problems need to be solved before the SIS is introduced into the school.

Teachers usually operate autonomously in the teaching-learning process which, because of its unpredictability and complexity, asks for professional discretion. More management information on how teachers function in the primary process may, for that reason, not result in fundamental changes in their activities.

\subsection{System use}

System use can differ with respect to the degree to which users transform their old activities and procedures into new ones. In many cases the innovation remains restricted to replacing old manual procedures by the same, but computer-assisted, ones or by adapting old operations a bit. The degree of innovative system use is influenced by:

- the degree to which the SIS enables substantial new ways of operation;

- the type of system use the school is aiming for and capable of;

- the degree to which the required implementation support is given.

SISs are until now mainly used for clerical work; computer-supported school management remains very limited. In some countries this may be due to the fact that the available SISs can not support school management work substantially. However in countries with powerful SISs it does not happen to a large extent either! Probably the use of the SIS in solving complex allocation problems causes less problems than benefiting from the computer's assistance in solving illstructured problems. The former does not ask much from the user since the data are 
entered and the SIS generates alternative solutions from which the manager can choose the one /she likes most. The latter type of system use requires much more since the users must:

- determine which information one would like to retrieve from the SIS;

- retrieve the information;

- interpret the output correctly;

- use the information in school decision-making;

- evaluate the results of the decisions taken.

The second and third skills are more or less technical, and managers can be trained to acquire them without great difficulty. The others are harder to acquire. To critically evaluate how a school functions, to detect problems and causes, and to design and evaluate remedies will require organisational development in most schools. That may well be a lengthy procedure and demand a great effort from schools and their managers. Nevertheless, the added value of sophisticated SISs is such that not trying to bring schools to this level of system usage would be a great loss.

\section{6 Effects of system use}

Research on the impact of system use is limited. Actually, large scale empirical research on its impact has just started in a number of countries - Hong Kong, The United Kingdom and The Netherlands.

Although user perceptions concerning the effects of system use are positive (a better quality of registration, available information and decision-making, more efficiency, and better allocations) strong empirical evidence for SIS effects is lacking. Although most users hate the idea that their SISs would be taken away and few users perceive negative effects, the quality of schooling until now is not considered to have improved as a result of SISs. The benefits are probably especially gained in the school administrative area.

\section{CONCLUSION}

Developing countries can benefit from the experience gained in developed countries in using a strategy for designing SISs, and implementing them with a high probability of SIS acceptance and use by the target users. Crucial elements of such a strategy are:

- the careful analysis of the school concerning its information demands and information flows;

- a definition of the SIS framework, containing a complete definition of all required capabilities that can be obtained from the SIS;

- the step-by-step participative design and development of prototypes for the modules in the SIS architecture in iterative design-test-redesign cycles, until it supports users widely in valuable and user-friendly ways, and system designers and users are happy with them; 
- the attention paid to the planning and managing of the innovation process (e.g. clear goals, feasible planning);

- the allocation of sufficient resources for the innovation and the dispersal of expertise among school staff;

- the stimulation of users by explaining, showing and letting them experience the potential of SISs;

- the preparation and training of users for system use at clerical and managerial level;

- the ensuring of the probability that users will experience success during the first innovative activities;

- the support for users during the introduction of the SIS by answering questions, by helping to solve problems and by developing support material they can refer to if problems occur.

Since individual schools do not have the expertise and resources to operate in the proposed way and commercial enterprises would have to invest too much in relation to the potential revenues, an active government is needed. The government must combine the required resources and expertise, and coordinate the entire process of design and implementation. If this condition is not fulfilled a waste of resources is unavoidable and school staff will not be able to work with professional SISs that can help them to enhance the quality of schools and schooling.

\section{REFERENCES}

Visscher, A.J. (ed.) (1991) Computer-assisted school administration and management: an international analysis. Special issue of the Journal of Research on Computing in Education, 24(1), 1-168.

Visscher, A.J. (1992) Design and Evaluation of a Computer-assisted Management Information System for Secondary Schools (doctoral dissertation), University of Twente, Enschede, The Netherlands.

Visscher, A.J. (ed.) (1996) Information Technology in Educational Management. Special issue of the International Journal of Educational Research, 25(4), 289390.

Visscher, A.J. (1994) A fundamental methodology for designing management information systems for schools. Journal of Research on Computing in Education, 27(2), 231-249.

Fung A.C.W. (1991) Computer assisted school administration in Hong Kong Joumal of Research on Computing in Education, 24(1), 120-145.

A.J. Visscher has been an assistant professor in the Faculty of Educational Science and Technology of the University of Twente since 1983. He received his Ph.D. for his doctoral thesis Design and Evaluation of a Computer-assisted Management Information System for Secondary Schools. In collaboration with others he designed and evaluated an integrated school information system (SIS) for secondary 
schools. Among the articles he has published on computerised SISs are special issues in the Journal of Research on Computing in Education and the International Journal of Educational Research. 